University of Wollongong

Research Online

Faculty of Social Sciences - Papers (Archive) Faculty of Arts, Social Sciences \& Humanities

$1-1-2017$

Promoting motor skills in low-income, ethnic children: The Physical Activity in Linguistically Diverse Communities (PALDC) nonrandomized trial

Anthony D. Okely

University of Wollongong, tokely@uow.edu.au

Louise L. Hardy

University of Sydney, louiseh@health.usyd.edu.au

Marijka Batterham

University of Wollongong, marijka@uow.edu.au

Philip J. Pearson

University of Wollongong, pearson@uow.edu.au

Kim Mckeen

University of Wollongong, kmckeen@uow.edu.au

See next page for additional authors

Follow this and additional works at: https://ro.uow.edu.au/sspapers

Part of the Education Commons, and the Social and Behavioral Sciences Commons

Research Online is the open access institutional repository for the University of Wollongong. For further information contact the UOW Library: research-pubs@uow.edu.au 


\title{
Promoting motor skills in low-income, ethnic children: The Physical Activity in Linguistically Diverse Communities (PALDC) nonrandomized trial
}

\author{
Abstract \\ This study reports the long-term effects of a professional learning program for classroom teachers on \\ fundamental motor skill (FMS) proficiency of primary school students from ethnically diverse \\ backgrounds. Design: A cluster non-randomized trial using a nested cross-sectional design. Methods: The \\ study was conducted in 8 primary schools located in disadvantaged and culturally diverse areas in \\ Sydney, Australia. The intervention used an action learning framework, with each school developing and \\ implementing an action plan for enhancing the teaching of FMS in their school. School teams comprised \\ 4-5 teachers and were supported by a member of the research team. The primary outcome was total \\ proficiency score for 7 FMS (run, jump, catch, throw, kick, leap, side gallop). Outcome data were analyzed \\ using mixed effects models. Results: Eight-hundred and sixty-two students ( $82 \%$ response rate) were \\ assessed at baseline in 2006 and 830 (82\%) at follow-up in 2010. Compared with students in the control \\ schools, there was a significantly greater increase in total motor skill proficiency among children in the \\ intervention schools at follow-up (adjusted difference $=5.2$ components, $95 \% \mathrm{Cl}[1.65,8.75] ; \mathrm{p} .=0.01$ ) and \\ in four of the seven motor skills. Conclusions: Training classroom teachers to develop and implement \\ units of work based around individual FMS is a promising strategy for increasing FMS among ethnically \\ diverse children over an extended period of time.

\section{Disciplines} \\ Education | Social and Behavioral Sciences

\section{Publication Details} \\ Okely, A. D., Hardy, L. L., Batterham, M., Pearson, P., Mckeen, K. \& Puglisi, L. (2017). Promoting motor skills \\ in low-income, ethnic children: The Physical Activity in Linguistically Diverse Communities (PALDC) \\ nonrandomized trial. Journal of Science and Medicine in Sport, 20 (11), 1008-1014.
}

\section{Authors}

Anthony D. Okely, Louise L. Hardy, Marijka Batterham, Philip J. Pearson, Kim Mckeen, and Lauren M. Puglisi 


\section{TITLE}

2 Promoting motor skills in low-income, ethnic children: The Physical Activity in Linguistically

3 Diverse Communities (PALDC) nonrandomized trial

4

5

6

8

9

10

11

12

13

14 


\section{STRUCTURED ABSTRACT}

\section{Objectives}

17 This study reports the long-term effects of a professional learning program for classroom

18 teachers on fundamental motor skill (FMS) proficiency of primary school students from

19 ethnically diverse backgrounds.

\section{Design}

21 A cluster non-randomised trial using a nested cross-sectional design.

\section{Methods}

23 The study was conducted in 8 primary schools located in disadvantaged and culturally diverse

24 areas in Sydney, Australia. The intervention used an action learning framework, with each school

25 developing and implementing an action plan for enhancing the teaching of FMS in their school.

26 School teams comprised 4-5 teachers and were supported by a member of the research team. The

27 primary outcome was total proficiency score for 7 FMS (run, jump, catch, throw, kick, leap, side 28 gallop). Outcome data were analysed using mixed effects models.

\section{Results}

30 Eight-hundred and sixty-two students (82\% response rate) were assessed at baseline in 2006 and $31830(82 \%)$ at follow-up in 2010. Compared with students in the control schools, there was a

32 significantly greater increase in total motor skill proficiency among children in the intervention

33 schools at follow-up (adjusted difference=5.2 components, 95\% CI $[1.65,8.75] ; \mathrm{P}=0.01)$ and in

34 four of the seven motor skills.

\section{Conclusions}


36 Training classroom teachers to develop and implement units of work based around individual

37 FMS is a promising strategy for increasing FMS among ethnically diverse children over an 38 extended period of time.

39 KEY WORDS: fundamental movement skills; physical education; physical fitness;

40 disadvantaged; culturally diverse. 


\section{INTRODUCTION}

44 Fundamental motor or movement skills (FMS) are defined as an organized series of basic

45 movement patterns in which two or more body segments are combined ${ }^{1}$. They are grouped into

46 locomotor, object control, and stability skills and include running, jumping, catching, throwing,

47 balancing, and twisting. These skills are considered the foundation of human movement as they

48 provide the basis for many of the specialized skills used in popular games and sports ${ }^{2}$. FMS

49 have also been shown to be related to several health outcomes such as higher levels of physical

50 activity, physical self-esteem, perceived competence, cardiorespiratory fitness, and lower levels

51 of adiposity ${ }^{3-5}$. For these reasons, FMS are considered an important component of primary

52 school physical education curricula.

54 Where representative data exist, FMS proficiency levels have been shown to be lower than what

55 might be expected for boys and girls of specific ages. In Australia, Hardy and colleagues ${ }^{6}$ found

56 that just under two-thirds of boys and nearly all girls (96\%) were not proficient in seven common

57 FMS assessed by the age of 11 years (run, vertical jump, side gallop, leap, catch, throw, and

58 kick). Similar results have been found in Irish children. O’Brien and Colleagues reported that

59 only $11 \%$ of 12 - and 13 -year olds were proficient in nine FMS ${ }^{7}$. Low proficiency levels are even

60 more common among primary school children from low socio-economic and ethnic backgrounds

$61{ }^{8}$. In Australia, these children are generally between one-and-a-half to three times less likely to

62 be as proficient as children from middle-to-high socioeconomic statuses and from English-

63 speaking backgrounds ${ }^{6}$. These data reinforce the need to provide additional support to children

64 from low income and non-English speaking backgrounds to increase their FMS proficiency. 
Most physical education (PE) in Australian primary schools is taught by classroom teachers. In

67 the state of New South Wales (NSW) (pop. 7.4 Million, June 2013), around 75\% of primary

68 schools use classroom teachers to teach $\mathrm{PE}^{9}$. Many of these teachers have undergone little

69 training in how to observe and teach FMS as part of their pre-service university training. As a

70 result, these teachers commonly report not feeling confident or competent in teaching FMS ${ }^{10}$. It

71 has been shown that training classroom teachers can result in significantly greater improvements

72 in FMS compared with non-trained classroom teachers ${ }^{11}$. To our knowledge, no studies have

73 examined the efficacy of training classroom teachers to teach FMS in schools with a high

74 proportion of children from low income and ethnic backgrounds, over an extended intervention

75 period (greater than three years) and targeted both locomotor and object control skills ${ }^{12}$.

77 Using a Quality Teaching and Learning Materials (QTLM) model and an Action Learning

78 framework ${ }^{13}$, this study aimed to build the capacity of primary schools with a high proportion of

79 children from low income and ethnic backgrounds, to promote children's competency in FMS.

80 Classroom teachers were trained to develop and implement lessons that met curricular outcomes

81 and provided developmentally appropriate physical activity experiences for students. The

82 QTLM is a school-based professional development model that uses the action learning principles

83 proposed by Kemmis and McTaggart's ${ }^{14}$. It provides a structured approach to school-based

84 professional development where a group of schools all work on the same area of change. ${ }^{15}$ The

85 purpose of this paper was to report the long-term impact of this school-based intervention on the

86 FMS of students, in primary schools with a high proportion of students from low-SES and

87 culturally diverse backgrounds. 


\section{METHODS}

90 The reporting of this study has been according to the TREND Statement ${ }^{16}$, CONSORT 2010

91 checklist ${ }^{17}$, and CONSORT statement: extension to cluster randomised trials ${ }^{18}$.

93 The Physical Activity among Linguistically Diverse Communities (PALDC) study was a non-

94 randomised cluster trial, using a nested cross-sectional design ${ }^{19}$ and comparing a whole-of-

95 school intervention with an active control condition. This design was selected over a nested

96 cohort design because the aims of the PALDC study were to bring about environmental-level

97 rather than individual-level changes ${ }^{20}$. Participants were recruited from eight government

98 (public education) primary schools in Western Sydney, Australia. These districts were pre-

99 selected by the NSW Department of Education and Communities (DEC), and the primary

100 schools within each district were selected on the basis of containing schools with a high

101 proportion of students from culturally diverse backgrounds. Within each school, all students

102 participated in the intervention, but only students in Grades 1, 3 and 5 were assessed at baseline

103 and Grades 2, 4, and 6 at 44-month follow-up. As a nested cross-sectional study, this meant

104 different students were assessed at each time point.

106 The study was approved by the Human Research Ethics Committee at the University of

107 Wollongong (HE06/182) and the State Education Research Approval Process (SERAP) of the

108 NSW DEC. Active consent from parents/carers was required for the students to participate in the

109 study and information sheets and consent forms were translated into Arabic and other languages,

110 as required. Data were collected within each school setting. Recruitment of schools occurred in

111 May and June 2006. The funding organisation had no role in the collection, analysis or 
112 interpretation of data. It was a requirement for them to approve the manuscript prior to

113 publication.

114

115 The PALDC intervention took a whole-of-school health promotion approach ${ }^{21}$. Using an Action

116 Learning framework ${ }^{15}$, each school developed an action plan for the intervention targeting the

117 structure and delivery of FMS and school sport (with a focus on initiating a sustainable change in

118 the delivery of FMS in their school context), modifying the physical and social environment in

119 the school, and developing links with the home and local community. These action plans were

120 similar across all schools. Schools nominated a team of 4-5 teachers (one per Stage [Grades K, 1-

121 2, 3-4, and 5-6] plus an Executive Teacher [Principal or Deputy Principal]) to be part of the

122 school "team". One member of the school team was designated the "Program Champion." Their

123 role was to be the school liaison for the research team for the project and to be the team leader

124 within the school for the project. A member of the research team was assigned to each school

125 and acted as a "critical friend." This involved helping identify relevant research and resources for

126 the development and implementation of the school's action plan, explaining the rationale for the

127 project to other school staff, and providing feedback on the implementation process to the school 128 team.

130 School teams participated in three workshops supported by personnel from the NSW DEC

131 Curriculum K-12 Directorate. This included a one-day planning workshop in Term 2, 2006 as an

132 introduction to the PALDC Project and the QTLM model and a two-day workshop in Term 3,

1332006 for schools to develop an action plan that would drive sustainable change in the area of

134 FMS and that met the needs of the students at their school. An additional final sharing workshop 
135 in March 2010 was held to provide an opportunity for schools to share the progress of the

136 program in their school towards the end of the project. All members of the school team in each

137 school attended the first two workshops and two members of each school team attended the final

138 sharing workshop. Interviews were held with the Principal and teachers in the control school to

139 gauge if they knew about the interventions occurring in the PALDC schools. None of the staff

140 were aware of the details of the intervention and there was no threat of contamination.

142 Intervention schools also worked as part of a cluster group on this project. This provided

143 opportunities for the schools to network and share ideas and to work towards the goals of whole-

144 of-school change in teaching and learning in FMS, increasing opportunities for students to be

145 more active throughout the school day, and strengthening community partnerships and

146 communication regarding healthy and active lifestyles.

148 The implementation plan for this Project was based on the Quality Teaching and Learning 149 Materials (QTLM) ${ }^{22}$ model developed by the NSW Department of Education and Communities

150 13. QTLM is a process for effecting school change based on a model of action research. The

151 QTLM model allowed school teams to work towards significant whole-of-school change by

152 building a supportive leadership team to facilitate identified change.

154 The control schools were asked to continue with their current PE programs and were provided

155 with information and professional development at the completion of the follow-up data

156 collection period. In addition, a member of the research team (ADO) met with the Principal of

157 each of the four control schools and offered them professional development and resources in an 
158 area not related to PE. Each school identified an area of concern such as bullying, peer support

159 and mentoring for beginning teachers. The research team and Curriculum Support Directorate of

160 the NSW DEC provided this professional development.

161

162 Baseline data were collected between June and September 2006 and 44-month follow-up data

163 were collected between February 2010 and March 2010. At each time point, a team of up to 19

164 teachers, blinded to group allocation, were seconded to the project as data collectors. The data

165 collectors attended a five-day orientation and training program prior to data collection. This

166 program provided background and justification for the study, and training in anthropometry,

167 questionnaire administration, FMS assessments and measurement of cardiorespiratory

168 endurance. The field teams were also provided with a minimum of two practice days in schools

169 prior to data collection. All data collectors were required to reach $99 \%$ inter-observer agreement

170 for all anthropometry measures and $80 \%$ inter-observer agreement for all FMS assessment

171 against pre-coded videotapes. ${ }^{23}$

172

173 The primary outcome for the study was FMS proficiency. Children performed seven FMS (sprint

174 run, vertical jump, catch, over-arm throw, kick, leap, and side gallop), and these were measured

175 using the Get skilled: Get active process-oriented checklists ${ }^{24,25}$. The skills assessed form the

176 basis of common activities and sports played by children. FMS proficiency was assessed by

177 scoring each component of each skill as present or absent. Briefly, children performed each skill

178 the required number of times according to the instructions. If they demonstrated the skill

179 component consistently (defined as $80 \%$ of the time for the sprint run and as four out of five

180 trials for the other skill components), they were recorded as possessing that skill component. The 
181 number of components of each skill correctly demonstrated by each child was summed to give a

182 score for each skill. There were five components assessed for the side gallop and six components

183 for all other skills. The scores for all seven skills were also added to calculate the total FMS

184 proficiency. The maximum score possible for the total score was 41 . Detailed information on the 185 validity and reliability of the skills and their components can be found in the supplementary file.

187 For students in Grades 3 and 5 at baseline and in Grades 4 and 6 at follow-up, cardiorespiratory

188 endurance (secondary outcome) was assessed using the Multistage Fitness Test (PACER) ${ }^{26}$.

189 Students were required to run and shuttle back between two lines placed 20m apart, at increasing

190 speeds. Scores were recorded as the level and shuttle reached in the test and converted to the

191 number of laps completed to provide a continuous variable for analyses.

192

193 Demographic data were collected from consent forms and parent questionnaires, and included 194 language most spoken at home (to determine ethnicity), postcode of residence, the highest level 195 of education completed by each parent, and the sex and date of birth of their child. Postcode of 196 residence was used as a proxy for socioeconomic status (SES), based on the Australian Bureau of 197 Statistics' Index of Relative Socioeconomic Disadvantage, and was used to rank children in 198 deciles of SES ${ }^{27}$.

200 Interviews were conducted with staff in each intervention school during 2010 (post-intervention) 201 to gather their feedback on the role the PALDC project had on their understanding of the change 202 process in schools and their understanding of the PE curriculum and on FMS. Notes were taken 203 by the Project Officer during these interviews, written up, and compared across schools to 
204 identify common themes that emerged for each of these areas across the intervention schools.

205 Interview data were supplemented with informal observational data collected by research staff on

206 the effect of the intervention on the school environment and on links with the home and local

207 community. The notes were also analysed thematically to provide supporting evidence on the

208 effectiveness of the intervention on these aspects of their school action plan. Critical friends also

209 documented the professional learning provided to staff in each of the schools, and what occurred

210 in response to the professional learning in terms of the writing and implementation of the

211 specific action plans that each school was asked to develop.

212

213 School allocation to intervention or control was done by the NSW DEC, independent of the

214 research team. To minimize potential bias due to non-randomization, intervention schools were

215 matched as closely as possible with control schools on demographic variables such as student

216 population, proportion of students from ethnic and low-income backgrounds, and geographic

217 location of the school (located in the same District). None of the researchers involved in working

218 with the intervention schools as critical friends were involved in the assessments.

220 As allocation to intervention or control group was at the school level, the analysis was performed

221 using a mixed effects model to account for random subject effects within each group ${ }^{16}$.

223 Data were analysed using the procedures outlined in Murray ${ }^{19}$ for a nested cross-sectional

224 design. This model has a fixed effect for group (control or intervention), school, and time

225 (baseline or follow-up) as a categorical variable. School grade, sex and the ethnicity of students

226 (defined as language spoken most at home) were modelled as covariates. The main estimate of 
227 interest (group by time interaction) was also included as a fixed effect. Time and the time-by-

228 school (group) terms were modelled as random effects to account for the school level clustering.

229 The PROC MIXED procedure in SAS v9.1 (SAS Institute Inc. Cary NC) was used for all

230 analyses. Data were analysed from November 2011 to June 2012.

232 RESULTS

233 All four schools initially approached to be intervention schools in the project agreed and nine

234 schools were approached for the four matched control schools. All eight schools (four

235 intervention and four control) that participated in the baseline assessments from June to

236 September 2006 were followed up between February and March 2010. A flow diagram of study

237 recruitment is shown in Figure 1.

239 A total of 1053 students and their parents were approached at baseline. Of these, 862 students 240 completed baseline assessments (82\% response rate) with 527 parents returning questionnaires

241 (50\% response rate). A total of 1016 students and their parents were approached at 44-month

242 follow-up. Of these, data were collected from 830 students (82\% response rate) with 301 parents

243 completing questionnaires (30\% response rate).

245 Demographic characteristics of the students at baseline and follow-up are presented in Table 1

246 and show that the sample was ethnically diverse and from low-income communities.

247 Approximately one-quarter of students were from English-speaking backgrounds, well below

248 that reported nationally $(84 \%)^{27}$. Just over half the sample was from Middle-Eastern speaking

249 backgrounds and around one-fifth was from Asian-speaking backgrounds. These proportions 
were well above those reported nationally (1.2\% for Middle-Eastern and 2.3\% for Asian

251 backgrounds) ${ }^{27}$.

253 Less than half of parents surveyed at baseline had completed high school (Grade 12) and this

254 proportion, whilst slightly higher at follow-up, was still below 60\%. Around one-third of parents

255 had completed Grades 9, 10, or 11, whilst between $10 \%$ and $20 \%$ had either never attended 256 school or only had a Grade 8 education level.

258 The project was also successful in recruiting low-income families. Almost all the sample (99\% at

259 baseline and $97 \%$ at follow-up) were in the two lowest deciles on the Australian Bureau of

260 Statistics’ Index of Relative Socioeconomic Disadvantage.

262 Table 2 shows the primary and secondary outcomes for the intervention and control groups at 263 baseline and follow-up. Cohen d's showed that there were small beneficial effects on all FMS

264 outcomes, with these being statistically significant for total FMS score $(\mathrm{p}=0.009)$, sprint run

$265(\mathrm{p}=0.001)$, vertical jump $(\mathrm{p}=0.006)$, catch $(\mathrm{p}=0.02)$ and the leap $(\mathrm{p}=0.004)$. The results for the 266 catch were due to a smaller decline in the intervention group compared with the control group 267 over the intervention period. The effect size for cardiorespiratory endurance was small and not 268 statistically significant.

270 Analyses of the interview data collected post-intervention indicated that the intervention was

271 somewhat successful in increasing teachers' understanding of the change process and of the PE

272 curriculum and FMS in their schools. These data showed that the most success in understanding 
273 the change process was among teachers who were part of the school team. These teachers

274 reported being more aware of the steps required to bring about change in their school. However,

275 they believed that the project was not generally successful in enhancing other teachers'

276 understanding of the change process in their schools. In addition, teachers who were part of their

277 school committee identified through the interviews a number of barriers they encountered to

278 bringing about change in their school. These included a lack of support from the school

279 executive, especially the Principal, the high turnover in staff over the four years of the project,

280 negative attitudes towards change from some of the staff, and the lack of equipment and facilities 281 available.

282

283 In all schools, the project team completed some form of professional learning in writing units of 284 work and in how to teach FMS. This was delivered by a Senior Curriculum Officer from the 285 NSW DEC and was well received by school staff. In three of the schools, a Scope and Sequence 286 (overview of content to be covered in a specific key learning area, in this case physical 287 education) was written for each stage and the staff wrote units of work for each FMS. In these 288 same three schools, there was evidence that staff were using these units and teaching FMS on a 289 regular basis. In addition, most staff at these schools were more aware of explicit teaching points 290 relating to development of FMS as a result of the project.

\section{DISCUSSION}

293 The purpose of this study was to assess the effect of an FMS intervention, which focused on the 294 up-skilling of classroom teachers in FMS in ethnically diverse Australian primary schools.

295 Overall, student response rates were high, especially given the ethnic diversity of the sample and 
296 the need for written parental consent for students to participate. Compared with children

297 allocated to control schools, children who participated in the PALDC intervention experienced

298 small beneficial effects on overall skill proficiency and on four of the seven individual

299 fundamental movement skills (sprint run, vertical jump, catch, and leap).

301 The effect sizes found are similar to that found in a recent systematic review for overall FMS

302 proficiency, and for locomotor and object control skills, ${ }^{28}$ but slightly smaller than the effect

303 sizes found in another systematic review ${ }^{11}$. The reason for the smaller effect sizes than the

304 Morgan review could be that this review included some studies that were in community-based

305 settings (such as after school programs). In addition, several of the studies in the review were

306 implemented by trained PE teachers or personnel external to the school, such as coaches or

307 researchers.

309 The results compare favorably with other primary school interventions designed to improve

310 children's FMS through training classroom teachers. McKenzie et al. ${ }^{29}$ reported similar effect

311 sizes for the catch and kick (0.29 and 0.09, respectively), a larger effect size for the over-arm

312 throw (0.27) and a slightly smaller effect size for total FMS proficiency (0.20). While their

313 intervention was with a similar number of students and a similar duration, they used product

314 rather than process methods to assess FMS, and only examined three object control skills, so the

315 total FMS scores are not comparable. The lower finding for the over-arm throw in our study is

316 interesting and may be explained by differences in the way the skill was assessed. McKenzie and

317 colleagues tested the ability of children to hit a target when throwing (accuracy test; i.e., product- 
318 oriented assessment) whereas this study focused on technique when throwing an object as far as

319 possible (i.e., process-oriented assessment).

321 We found the differences between intervention and control groups were highest for the catch and

322 the locomotor skills (sprint run, vertical jump, leap, and side gallop, all had effect sizes >0.20).

323 These findings are similar to those reported by van Beurden et al. ${ }^{30}$ who found the largest

324 differences between intervention and control groups were for the sprint run, side gallop, catch,

325 and vertical jump. It could be that these skills do not require specialized equipment, in our

326 experience are easier for classroom teachers to learn and hence they feel more confident in

327 teaching these skills. This may be due to the overwhelming majority of primary school teachers

328 being female, and these five skills (catch, sprint run, vertical jump, leap, and side gallop) being

329 the skills in which females have the highest levels of proficiency based on data from the NSW

330 Schools Physical Activity and Nutrition Survey. ${ }^{31}$

332 We found the smallest differences between intervention and control groups for the over-arm

333 throw and kick. This is somewhat similar to van Beurden and colleagues ${ }^{30}$ who reported smaller

334 improvements for the over-arm throw and McKenzie et al. ${ }^{29}$ who found smallest improvements

335 in the kick. Reasons for this may be that the over-arm throw and kick are more complex skills,

336 with a greater number of components and a movement pattern that occurs very quickly compared

337 with the other skills ${ }^{32}$. This may also be a reason why these skills typically show lower

338 proficiency levels ${ }^{6}$. Because of this higher level of complexity in the throw and kick, we have

339 found that teachers may also require more training in teaching these skills. In the context of how

340 children are taught to develop proficiency in these skills, it is important for them to throw or kick 
341 a ball as hard as they can for components such as the follow through, and rotation of the body

342 during the preparatory phase to develop ${ }^{1}$. Schools may not have had the physical space, nor

343 teachers with the confidence to allow students to do this safely in a PE lesson.

345 The null finding for cardiorespiratory endurance was not surprising given that the intervention 346 content did not focus on increasing physical activity, but rather on FMS. The decline seen in 347 cardiorespiratory fitness levels, especially in the control group, could be due to the time of year 348 assessed - follow-up was immediately after a 6-week summer holiday break - which has been 349 shown to adversely effect children's fitness levels. ${ }^{33}$ Interventions that do target increasing 350 physical activity in primary schools have been shown to be effective in increasing student fitness 351 levels ${ }^{34}$.

353 Factors that may have contributed to significant improvements seen for total FMS include 354 schools being able to design and implement learning experiences that were most appropriate for 355 their school (not a "one-size-fits-all" approach). There was considerable variation in how 356 intervention schools implemented their programs. One school delivered the PALDC intervention 357 for 15-minutes directly after morning recess, three times a week and involved the whole school. 358 Another school structured their units of work by stages, (adjacent grades; e.g., Grades $1 \& 2,3 \&$ $3594,5 \& 6$ ) with lessons scheduled twice a week for 30 minutes at a time. A third school, with 360 approximately 800 students, wrote units of work for each Grade and organized their timetable so 361 that all classes in that Grade (i.e., between 4 and 6 classes) participated at the same time. There 362 was no evidence that the fourth intervention school developed new units of work or changed 363 their current practice. This was due to the high turnover of staff on the school team and lower 
364 levels of support and engagement from the school principal. The school also felt that they were

365 doing enough to promote FMS through their sport program; however, our observations and

366 discussions with other staff suggest this program consisted of children participating in sport with

367 no structured lessons or specific teaching and instruction.

368

369 A common element in all implementation models was multiple classes being timetabled at the

370 same time. School teams did this as they believed it would facilitate greater participation by all

371 classroom teachers in a specific Grade or Stage. It allowed the pooling of resources such as staff,

372 the option of including a range of learning experiences (stations, partner activities), and ability

373 grouping of students for some activities. It also made teachers more accountable because they

374 were being relied on by the other teachers to ensure the lessons could be implemented as

375 planned. Finally, teachers could usually self-select an activity they felt most comfortable

376 teaching from a number that were planned to be conducted.

378 Another factor that enhanced implementation was the "ownership" staff felt with the program.

379 As each school team was responsible for developing their own program, they felt some

380 responsibility to implement it on a whole-of-school basis. As a result of progressing through the

381 Quality Teaching and Learning Materials process, staff also felt excited that they now had an 382 action plan for improving FMS. That is, a model they could follow to develop units of learning

383 over a calendar year. However, it was mostly the members of the school team who benefitted 384 from the intervention and ways need to be found to better engage other teachers in the schools to 385 be trained and implement the action plan developed for their school. 
387 The role of the school Principal to support interventions such as PALDC cannot be 388 underestimated. Their support took a number of roles, including being part of the school action 389 team, providing funding to purchase equipment, and providing relief from teaching for the

390 Program Champion, allowing them the time to work on the project and meet with their critical

391 friend. The Principal also has the ability to ensure the sustainability of the project through

392 incorporating the action plan for the project into the School Plan. This would also guarantee the 393 commitment and responsibility of all staff to whole school change. However it should also be

394 acknowledged that the principal could be a barrier to the success of the intervention, as was the 395 case in at least one of the schools.

397 Observation and interview data from schools showed that minimal changes were made to the 398 links between the school and the home and local community. Some of these changes were 399 embedded into aspects of the school life, such as parent newsletters. In addition, teachers 400 reported anecdotally that they believed there had been more parents involved in school sport and

401 fitness activities and more information provided to parents around FMS and physical activity as a 402 result of the PALDC intervention. The main barrier to change reported by teachers was the high 403 number of parents who did not speak English, and the high levels of television viewing and 404 internet use among families.

405

406 Strengths of this study include the recruitment of a large sample of children from ethnically 407 diverse and low-income families and the high response rates achieved. Limitations include the 408 inability to examine changes within individual students due to the longer follow-up period and 409 that schools were not able to be randomly assigned and as such were matched. It was also 
410 beyond the resources of the PALDC intervention to systematically and independently collect

411 data on the fidelity of the intervention developed by each school, to video assess the FMS -

412 which would have allowed greater measurement scrutiny, or to include a stability skill as one of

413 the seven assessed. A further limitation was the lack of an objective measure of changes in

414 physical activity, which would have provided useful information on the role of increasing FMS

415 in the promotion of school-based physical activity. Given the relationship between FMS and 416 physical activity, these results have the potential to impact on physical activity participation.

\section{CONCLUSION}

419 In conclusion, our research shows that a low-cost approach involving a partnership, between the 420 public education sector, selected schools, and researchers, can be effective. Interventions that 421 require minimal resources and seek to up-skill classroom teachers within the schools to develop

422 and implement developmentally appropriate lessons to improve FMS hold promise to improve 423 classroom teachers' delivery of good quality FMS lessons, and can have an effect on targeted 424 outcomes.

\section{Practical implications}

427 - Classroom teachers can be trained to successfully bring about a change in their school's 428 curricula and environment to improve students' gross motor skills

- A committed and supportive school principal appears to be a key factor in ensuring $430 \quad$ sustained whole school change.

- Researchers should be mindful that the change process in schools can take longer than expected and be prepared to commit to long-term partnerships with schools. 
434 Competing Interests: None

435

436 Figure Captions

437 Figure 1. Sample selection and response rates at baseline (2006) and follow-up (2010)

\section{SUPPLEMENTARY FILES}

440 Supplementary File 1. Information on the validity and reliability of the checklists used to assess

441 the seven skills in this study 
442

443

444

445

446

447

448

449

450

451

452

453

454

455

456

457

458

459

460

461

462

463

464

465

466

467

468

469

470

471

472

473

474

475

476

477

478

479

480

481

482

483

484

485

486

487

\section{REFERENCES}

1. Gallahue DL, Donnelly FC. Developmental physical education for all children, 4th ed, Champaign, IL, Human Kinetics; 2003.

2. Gabbard CP. Lifelong motor development 5th ed, San Francisco, CA, Pearson; 2008.

3. Cattuzzo MT, dos Santos Henrique R, Ré AHN, et al. Motor competence and health related physical fitness in youth: A systematic review. J. Sci. Med. Sport. 2016; 19(2):123-129.

4. Holfelder B, Schott N. Relationship of fundamental movement skills and physical activity in children and adolescents: A systematic review. Psychol. Sport Exerc. 2014; 15(4):382-391.

5. Lubans DR, Morgan PJ, Cliff D, et al. Fundamental movement skills in children and adolescents: a review of associated health benefits. Sports Med. 2010; 40:1019-1035.

6. Hardy LL, Reinten-Reynolds T, Espinel P, et al. Prevalence and correlates of low fundamental movement skill competency in children. Pediatrics. 2012; 130:e390-e398.

7. O'Brien W, Belton S, Issartel J. Fundamental movement skill proficiency amongst adolescent youth. Phys. Educ. Sport Pedag. 2016; 21(6):557-571.

8. Barnett LM, Lai SK, Veldman SL, et al. Correlates of Gross Motor Competence in Children and Adolescents: A Systematic Review and Meta-Analysis. Sports Med. 2016:1-26.

9. Hardy LL, King L, Espinel P, et al. NSW Schools Physical Activity and Nutrition Survey (SPANS) 2010: Full Report. Sydney, NSW: NSW Ministry of Health; 2010.

10. Morgan PJ, Hansen V. Classroom Teachers' Perceptions of the Impact of Barriers to Teaching Physical Education on the Quality of Physical Education Programs. Res. $Q$. Exerc. Sport. 2008; 79:506-516.

11. Morgan PJ, Barnett L, Cliff DP, et al. Fundamental movement skill interventions in youth: systematic review and meta-analysis. Pediatrics. 2013; 132:e1361-e1383.

12. Lander N, Eather N, Morgan PJ, et al. Characteristics of Teacher Training in SchoolBased Physical Education Interventions to Improve Fundamental Movement Skills and/or Physical Activity: A Systematic Review. Sports Med. 2016; doi:10.1007/s40279-0160561-6.

13. Wright J. Physical education teacher education: sites of progress or resistance, in Gender and physical education: contemporary issues and future directions. Penney D, ed^eds. London, Routledge, 2006.

14. Kemmis S, McTaggart R. Participatory action research, in Handbook of qualitative research. Denzin K, Lincoln Y, ed^eds. 2nd ed. Thousand Oaks, Sage, 2002.

15. Wright J, Hearne D, Konza D, et al. The Gold Medal Fitness Project: a model for teacher change. Phys. Educ. Sport Pedag. 2008; 13:49-64.

16. Des Jarlias DC, Lyles C, Crepaz N. Improving the Reporting Quality of Nonrandomized Evaluations of Behavioral and Public Health Interventions: The TREND Statement. Am. J. Public Health. 2004; 94:361-366.

17. Moher D, Hopewell S, Schulz KF, et al. CONSORT 2010 Explanation and Elaboration: updated guidelines for reporting parallel group randomised trials. BMJ. 2010; 340:c869.

18. Campbell M, Elbourne D, Altman D. CONSORT statement: Extension to cluster randomised trials. $B M J .2004 ; 328: 702-708$. 
19. Murray DH. Design and Analysis of Group-Randomized Trials, New York, Oxford, Oxford University Press; 1998.

20. Stevens J, Murray DM, Catellier DJ, et al. Design of the trial of activity in adolescent girls (TAAG). Contemp. Clin. Trials. 2005; 26(2):223-233.

21. National Health and Medical Research Council. Effictive school health promotion: Towards health promoting schools. Canberra, ACT: NHMRC Health Advancement Standing Committee; 1996.

22. Groundwater-Smith S. Participative Learning: The School as a Learning Community and as a Member of a National Reform Organisation, in Learning Communities in Education. J. Retallick, B. Cocklin, Coombe K, ed^^eds. London, Routledge, 1999.

23. Hardy L, King L, Espinel P, et al. Methods of the NSW schools physical activity and nutrition survey 2010 (SPANS 2010). J. Sci. Med. Sport. 2011; 14(5):390-396.

24. NSW Department of Education and Training. Get skilled: Get active. A K-6 resource to support the teaching of fundamental movement skills, Ryde, NSW, NSW Department of Education and Training; 2000.

25. Okely AD, Booth ML. The development and validation of an instrument to assess children's fundamental movement skill ability [abstract]. 2000 Pre-Olympic Congress. Brisbane: Sports Medicine Australia; 2000:158.

26. Leger LA, Lambert J. A maximal multistage 20-m shuttle run test to predict VO2max. Eur. J. Appl. Physiol. 1982; 49:1-12.

27. Australian Bureau of Statistics. 2009-10 Year Book Australia, Canberra, ACT, Australian Government; 2010.

28. Logan SW, Robinson LE, Wilson AE, et al. Getting the fundamentals of movement: a meta-analysis of the effectiveness of motor skill interventions in children. Child Care Health Dev. 2012; 38(3):305-315.

29. McKenzie TL, Alcaraz JE, Sallis JF, et al. Effects of a physical education program on children's manipulative skills. J. Teach. Phys. Educ. 1998; 17:327-341.

30. van Beurden E, Barnett LM, Zask A, et al. Can we skill and activate children through primary school physical education lessons? "Move it Groove it": a collaborative health promotion intervention. Prev. Med. 2003; 36:493-501.

31. Booth M, Okely A, Denney-Wilson E, et al. NSW Schools Physical Activity and Nutrition Survey (SPANS) 2004: Full Report. Sydney: NSW Department of Health; 2006.

32. Payne VG, Isaacs LD. Human motor development: a lifespan approach, 3rd ed, Mountain View, CA, Mayfield; 1995.

33. Carrel AL, Clark RR, Peterson S, et al. School-based fitness changes are lost during the summer vacation. Arch. Pediatr. Adolesc. Med. 2007; 161(6):561-564.

34. McKay HA, Macdonald HM, Nettlefold L. Action Schools! BC implementation: from efficacy to effectiveness to scale-up. Br. J. Sports Med. 2015; 49(4):210-218. 